\title{
CONTRIBUIÇÕES DO PROGRAMA DE EXTENSÃO EM EDUCAÇÃO MATEMÁTICA NA FECLESC E NA COMUNIDADE EXTERNA
}

\section{CONTRIBUTIONS OF THE EXTENSION PROGRAM IN MATHEMATICAL EDUCATION IN FECLESC AND IN THE EXTERNAL COMMUNITY}

\author{
Antônio Anderson Oliveira Silva ${ }^{1}$; Dianara Figueirêdo Freire $^{2}$, Francisco Edisom \\ Eugenio de Sousa ${ }^{3}$
}

\begin{abstract}
RESUMO
É notória a defasagem no ensino de Matemática nas escolas, o que leva muitos professores a se perguntarem, diariamente: "Como ensinar Matemática? ou "O que devo fazer para que os meus alunos aprendam esse conteúdo de Matemática?". Por isso, não se pode deixar de pensar e de criar projetos/estratégias que fortaleçam o ensino de Matemática, pois a mesma é indispensável na formação do ser humano. Para tanto, existe a extensão universitária, que possibilita uma contribuição para a formação do discente que a vivencia, por meio de experiências desenvolvidas, que fortalecem o conhecimento do aluno e que visam promover a relação entre a universidade e a comunidade externa. A observação e a participação nas ações de extensão realizadas no Programa de Extensão: Formação Continuada em Educação Matemática, vinculado ao Laboratório de Educação Matemática da FECLESC/UECE - LaboMática, levou-nos ao seguinte questionamento: quais as contribuições do Programa de Extensão: Formação Continuada em Educação Matemática, dos anos de 2018 e 2019, na formação de licenciandos e comunidade externa? Diante dessa pergunta, este trabalho teve como objetivo refletir sobre as contribuições do Programa de Extensão: Formação Continuada em Educação Matemática, dos anos de 2018 e 2019, na formação de licenciandos e na comunidade externa. $\mathrm{O}$ artigo foi desenvolvido por meio de uma pesquisa participante, de natureza qualitativa, em que foram observadas ações realizadas interiormente e exteriormente à FECLESC. Assim, observaram-se várias atividades proporcionadas pelo Programa e suas contribuições na disseminação de metodologias para o ensino de Matemática e o Programa ainda colaborou para aperfeiçoar a formação inicial e continuada dos envolvidos no projeto, destacando-se a importância da extensão universitária e percebendo-a como uma peça fundamental na formação do professor, pois ela o aproxima do
\end{abstract}

\footnotetext{
${ }^{1}$ Graduando em Licenciatura em Matemática pela Faculdade de Educação, Ciências e Letras do Sertão Central (FECLESC). Rua Banabuiú, 71, Planalto do Banabuiú, Senador Pompeu, Ceará, Brasil, CEP: 63600-000. E-mail: andersonoliveirainfor@gmail.com.

ORCID iD: https://orcid.org/0000-0001-7919-8520.

${ }^{2}$ Mestranda em Ensino de Ciências e Matemática pelo Instituto Federal de Educação Ciência e Tecnologia do Ceará (IFCE). Serra do Vicente, S/N, Pasmado, Capistrano, Brasil, CEP: 62748-000. E-mail: dianarafigueiredo321@gmail.com.

iD ORCID iD: https://orcid.org/0000-0002-5901-7478.

${ }^{3}$ Doutor em Educação pela Universidade Federal do Ceará (UFC). Professor da Universidade Estadual do Ceará (UECE) e Prefeitura Municipal de Quixadá, Quixadá, Ceará, Brasil. Rua Laerte Pinheiro, 651, Centro, Quixadá, Ceará, Brasil, CEP: 63900-197.E-mail: francisco.eugenio@uece.br.
}

ORCID iD: https://orcid.org/0000-0002-2544-7103. 
fazer docente e também rompe a distância entre universidade e comunidade externa, entre universidade e escola.

Palavras-chave: Contribuições; Programa de Extensão; Educação Matemática; Formação inicial docente.

\begin{abstract}
The gap in the teaching of mathematics in schools is notorious, which leads many teachers to ask themselves day by day: "How to teach mathematics or what should I do to make my students learn this Mathematics content?" That's why anyone can't stop thinking and creating projects / strategies which strengthen the teaching of Mathematics, as it is indispensable in the formation of the human being. In the other hand, there is a university extension which contributes to the formation of the student who experiences it through developed experiences and strengthen student knowledge and which aims to promote the relationship between the university and the external community. The observation and participation in the extension actions perfomed in the extension program Continuing Education in Mathematics Education at FECLESC / UECE , leaded us to the question: "What are the contributions of the extension program Training Continued in Mathematics Education, from the years 2018 and 2019, in the training of undergraduate students and the external community?" About this question, the studying aims to reflect on the contributions of the Extension Program: Continuing Education in Mathematical Education, from the years 2018 and 2019, in the training of undergraduate students and in the external community. The participative research of a qualitative nature was necessary to develop the article which observed perfomed actions, internally and externally at FECLESC. Thus, we observed several activities provided by the Program and their contributions in the dissemination of methodologies for teaching Mathematics and the Program collaborated to improve the initial and continuing training of those involved in the project. By the way, highlighting the importance of university extension and realizing it as a fundamental part in teacher education, because it brings them close to teaching and breaks the distance between university and external community between university and school.
\end{abstract}

Keywords: Contributions; Extension Program; Mathematical Education; Initial teacher training. 


\section{Introdução}

Ao observarmos o contexto referente ao ensino dos conteúdos matemáticos, podemos averiguar a mesma discussão de décadas atrás, que pode ser resumida em uma pergunta: o que devemos fazer para melhorar o desempenho dos alunos em Matemática? Esta indag ação revela a preocupação de formadores dos professores que irão lecionar essa disciplina, de responsáveis pela gestão da educação e de docentes do ensino básico, que são os responsáveis diretos pelo ensino do conteúdo matemático, este, muitas vezes, já rotulado pelos alunos como difícil de aprender.

Contudo, olhando ao nosso redor, observamos a Matemática nos vários campos profissionais e em situações como: Biologia, Medicina, Tecnologias, Engenharias, dentro do comércio, em uma temperatura de um fogão, nas brincadeiras infantis e em outras inúmeras situações. Desse modo, podemos perceber a tamanha importância do ensino da Matemática. Assim, notamos que tanto o professor de Matemática quanto o graduando em formação inicial precisam estar em constante aprendizado, para seu aperfeiçoamento. Este último necessita conviver no seu futuro ambiente de trabalho, pois precisa inteirarse sobre a docência e sobre os desafios que irá enfrentar mais à frente.

É notória a defasagem no ensino de Matemática nas escolas, o que leva muitos professores a se perguntarem, diariamente: “Como ensinar Matemática? ou "O que devo fazer para que os meus alunos aprendam esse conteúdo de Matemática?". Observamos gestores e professores extremamente preocupados com os resultados negativos dos discentes nas avaliações, principalmente nas externas. Portanto, eles vivem em busca de estratégias para tentar amenizar os prejuízos dos educandos relacionados à não aprendizagem dos conteúdos, mas, muitas vezes, as tentativas falham quando se trata dos conteúdos matemáticos.

Por isso, não se pode deixar de pensar e de criar projetos/estratégias que fortaleçam o ensino de Matemática, pois a mesma é indispensável na formação do ser humano. Nessa perspectiva, com base nas dificuldades enfrentadas pelos professores em sala de aula, foi criado o Programa de Extensão: Formação Continuada em Educação Matemática, doravante denominado Programa de Extensão ou apenas Programa, com o intuito de contribuir com a prática dos docentes em exercício. Frequentemente, os 
professores têm dificuldades em ensinar tais saberes e esse Programa propõe o estudo e a vivência de metodologias que visam facilitar a aprendizagem dos alunos.

O referido Programa de Extensão é ligado ao Laboratório de Educação Matemática da FECLESC (LaboMática), na Faculdade de Educação, Ciências e Letras do Sertão Central (FECLESC), situada em Quixadá-CE, campus da Universidade Estadual do Ceará (UECE). Esse Programa é realizado na própria Faculdade e na comunidade externa, em escolas parceiras, nas quais desenvolve atividades como: minicursos/oficinas, palestras, seminários temáticos, encontros, entre outras atividades voltadas para o ensino/aprendizagem de Matemática.

Essas atividades são proporcionadas à comunidade externa, para professores atuantes na rede de ensino básico, em atividades de formação continuada, para alunos das escolas parceiras e ainda atende licenciandos de Matemática e de Pedagogia, com o objetivo de acrescentar experiências em suas formações, por meio de ações de ensino e extensão, também envolvendo temas voltados para a pesquisa, principalmente, com a participação de estudantes, sendo estes bolsistas do Laboratório e aqueles que se interessam e se envolvem nas ações de extensão e outras do LaboMática.

O Programa de Extensão conta com bolsistas remunerados e voluntários, vinculados à Pró-Reitoria de Extensão (PROEX) da UECE. No ano de 2018, ele contou com três bolsistas remunerados e um voluntário; no ano de 2019, participaram dois bolsistas remunerados. A presença no referido Programa foi fundamental para o desenvolvimento desses estudantes, participando de suas atividades de planejamento, realização, avaliação e, muitas vezes, da sistematização de dados, resultando em produções científicas.

A observação e a participação nas ações de extensão realizadas, nesse Programa, conduziu-nos ao seguinte questionamento, que norteou a realização dessa pesquisa: quais as contribuições do Programa de Extensão: Formação Continuada em Educação Matemática, dos anos de 2018 e 2019, na formação dos licenciandos e comunidade externa? Essa pergunta levou-nos à definição do seguinte objetivo: refletir sobre as contribuições do Programa de Extensão: Formação Continuada em Educação Matemática, dos anos de 2018 e 2019, na formação dos licenciandos e comunidade externa. 
Este artigo foi desenvolvido por meio de uma pesquisa qualitativa, do tipo participante, em que observamos, registramos dados e, por vezes, aplicamos questionários avaliativos em torno das ações de extensão realizadas no interior da FECLESC e na comunidade externa, proporcionadas pelo Programa de Extensão, tais como: oficinas em escolas de ensino básico do município de Quixadá e minicursos, oficinas e seminários temáticos na própria Faculdade, estes com a participação de licenciandos da FECLESC e de pessoas da comunidade externa, sendo estes professores e estudantes de outras Faculdades.

Para o embasamento teórico deste trabalho, usamos como referência os seguintes autores: Freire e Coelho (2018), Borba e Penteado (2016), Lorenzato (2006) e Souza et al. (2011), os quais deram suporte à nossa reflexão acerca das contribuições desse Programa de Extensão na formação de licenciandos da FECLESC, principalmente, dos cursos de Pedagogia e de Matemática, bem como para a comunidade externa.

\section{Atividades desenvolvidas pelo Programa de Extensão na FECLESC}

Durante o período no qual foram realizadas e observadas as atuações do Programa de Extensão: Formação Continuada em Educação Matemática, foi notado o desenvolvimento de várias atividades, que intercalaram-se entre ações realizadas com docentes a discentes. Dentre outras ações, foram desenvolvidos quatro minicursos nos anos de 2018 e 2019, sendo dois deles com carga horária de 20 horas e os outros dois com 16 horas de duração, promovidos dentro da própria Faculdade, com a participação de estudantes da FECLESC e de pessoas da comunidade.

Essas atividades proporcionaram que os participantes conhecessem novas metodologias e, ainda, deram a oportunidade de apreciarem a discussão sobre novos temas que fazem parte da área da Matemática, que, com frequência, não são tratados na graduação. Alguns minicursos trataram de conteúdos matemáticos - Introdução a Espaços Métricos e Tópicos de Teoria dos Números - e outros foram voltados a metodologias e tendências ligadas à Educação Matemática - O Ensino de Fração com Material Didático e O Ensino da Matemática com o uso de Tecnologias da Informação e da Comunicação (TIC). 
Os minicursos atenderam a um público com o mínimo de 10 e o máximo de 20 cursistas, sendo eles graduandos de Pedagogia e de Matemática da FECLESC, professores da Educação Básica e outros licenciandos de cursos afins, da mesma Faculdade, que se interessaram pelos temas abordados. No desenvolvimento das atividades, alguns participantes ressaltaram a importância do desenvolvimento dessas atividades, pois as mesmas propiciaram a ampliação das discussões dentro do âmbito universitário sobre ensino e Matemática, considerando as lacunas, às vezes, existentes nos cursos, mesmo sendo de licenciatura.

O minicurso Introdução aos Espaços Métricos foi realizado no primeiro semestre de 2018, com 16 horas de atividades. Esse foi um dos dois eventos que teve como foco o conteúdo de Matemática, o que também é uma das metas do LaboMática: trabalhar os conteúdos que vão ser lecionados. Nesse sentido, corroboramos com Lorenzato (2008, p. 3), ao afirmar: "Considerando que ninguém consegue ensinar o que não sabe, decorre que ninguém aprende com aquele que dá aulas sobre o que não conhece. [...]”. Um dos momentos dessa atividade foi registrado na seguinte figura.

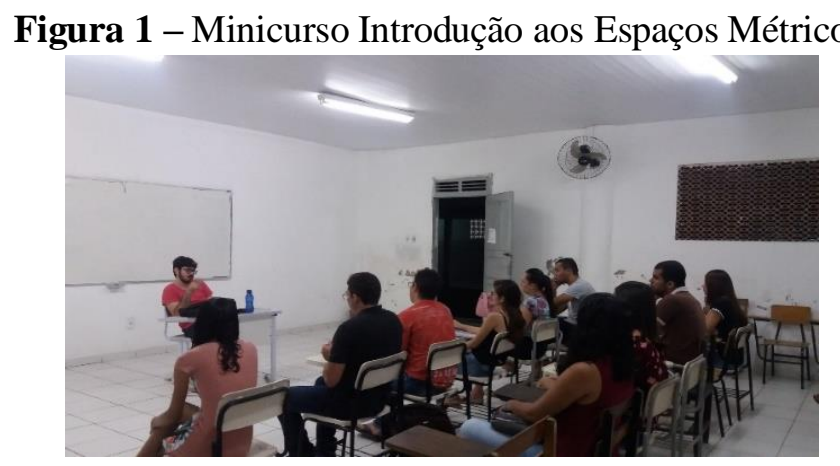

Fonte: Autores (2020).

Outro minicurso foi O Ensino de Fração com Material Didático, em 2019, que permitiu aos cursistas uma experiência com o material didático manipulável Fracsoma. $\mathrm{Na}$ avaliação de um participante sobre a importância dessa ação, ele registrou que: "Influenciou bastante, pois se aprendo isso logo no início do curso, terei melhor entendimento para aplicá-lo na continuação da minha vida acadêmica e profissional em sala de aula". A fala desse estudante reforça a necessidade de atividades práticas, na universidade e nas escolas, durante todo o curso de licenciatura, desde seu início. 
Esse depoimento ressalta a influência desse Programa na propagação de atividades que visam o aperfeiçoamento do ensino da Matemática, visto que ele está proporcionando um maior contato dos graduandos e professores com temas relevantes da Educação Matemática e também de conteúdos de Matemática, que, mesmo nos cursos de caráter metodológico, como o uso de material didático, envolvem discussões sobre os conteúdos contemplados com o uso de determinado recurso. A seguir, mostramos o registro de um dos momentos desse minicurso com o uso do Fracsoma.

Figura 2 - Minicurso: O Ensino de Fração com Material Didático.

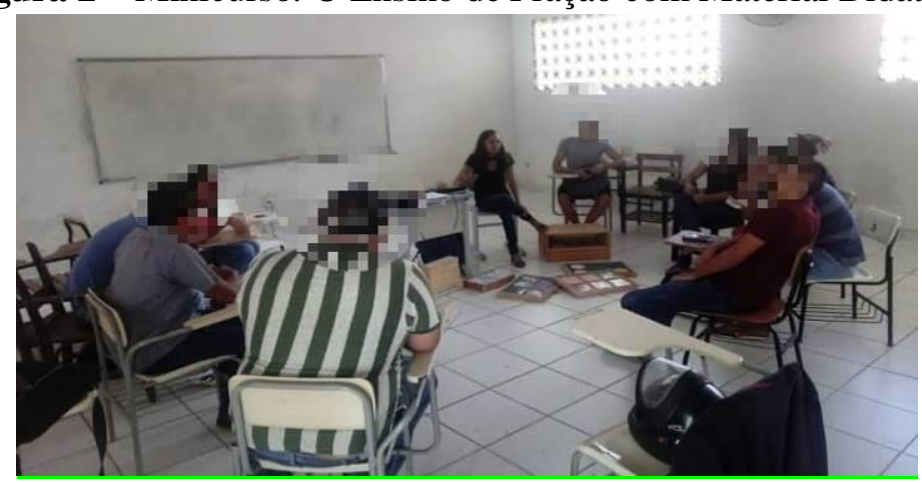

Fonte: Autores (2020).

O uso do Material didático (MD) é algo que colabora com o desenvolvimento da aprendizagem, desde que seu uso seja planejado e que possua finalidade dentro do assunto abordado. Desse modo, para que a construção do conhecimento matemático aconteça, "faz-se necessária também a atividade mental, por parte do aluno. E o MD pode ser um excelente catalisador para o aluno construir seu saber matemático" (LORENZATO, 2006, p. 21). Somando-se aos inúmeros MD já existentes, mesmo que, muitas vezes, as escolas não disponham desses recursos e/ou os professores não os utilizem, nos últimos anos, principalmente, passamos a contar com recursos tecnológicos informatizados, o que motivou a realização de um minicurso sobre essa temática.

A experiência com o minicurso $O$ Ensino da Matemática com o uso de Tecnologias da Informação e da Comunicação - TIC, realizado também no ano de 2019, foi importante e desafiadora para os participantes, pois o intuito do mesmo era apresentar essa tendência da Educação Matemática e, ainda, levar para os envolvidos ferramentas que pudessem auxiliá-los em suas atuações profissionais, a partir da utilização de alguns 
desses recursos na formação inicial. A figura 2 mostra um momento dessa ação de extensão.

Figura 3 - Minicurso: O Ensino de Matematica com o uso de TIC.

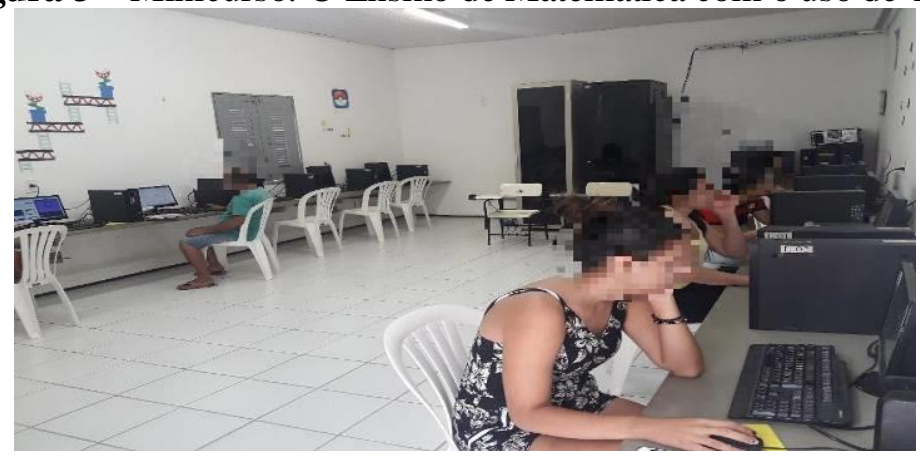

Fonte: Autores (2020).

Um estudante e participante desse minicurso ressaltou em sua fala a importância da execução e apresentação dessa temática, ao relatar que "[...] o uso das TIC facilita a maior compreensão do conteúdo e principalmente desperta mais o interesse dos alunos pela aula, já que vivemos em um mundo cercado por tecnologias bem atrativas”. Através dessa fala, é possível perceber a visão sobre o uso das TIC na vida profissional de um docente. É essencial salientar a relevância do uso dessa tecnologia nas disciplinas dos próprios cursos de licenciatura, uma prática não frequente na FECLESC.

Como dito na fala do aluno, "vivemos em um mundo cercado de tecnologias". Essa afirmação evidencia a importância de os docentes estarem dispostos a se atualizar por meio de formações continuadas ou investigações pessoais, tomando para si essa atualização. Além de ser desafiador, é um processo que exige compromisso e interesse em buscar sempre melhorar o ensino-aprendizagem, utilizando ferramentas que estão disponíveis a seu favor. De acordo com Borba e Penteado (2016),

[...] À medida que a tecnologia informática se desenvolve, nos deparamos com a necessidade de atualização de nossos conhecimentos sobre o conteúdo ao qual ela está sendo integrada. Ao utilizar uma calculadora ou um computador, um professor de matemática pode se deparar com a necessidade de expandir muitas de suas ideias matemáticas e também buscar novas opções de trabalho com os alunos. Além disso, a inserção de TI no ambiente escolar tem sido vista como um potencializador das ideias de se quebrar a hegemonia das disciplinas e impulsionar a interdisciplinaridade (BORBA; PENTEADO, 2016, p. 64-65). 
A utilização de $\mathrm{MD}$, em qualquer formato ou modalidade, contribui de maneira significativa com a formação dos licenciandos, não só de Pedagogia, mas também daqueles que atuarão com adolescentes e adultos, no caso, aqui, dos estudantes de Matemática. Consoante Lorenzato (2006, p. 30): “A experiência tem mostrado que o MD facilita a aprendizagem, qualquer que seja o assunto, curso ou idade, o que conflita com a crença de que MD só deve ser usado com criança. [...]”. Relevante também é a interação dos licenciandos com o público com o qual irão atuar, os alunos.

O contato com os discentes é sempre algo frequente, sendo exercido pelas ações desse Programa de Extensão. Um exemplo foi a apresentação do LaboMática, realizada para os estudantes da turma de $4^{\circ}$ ano de uma escola de Ensino Fundamental, filantrópica e conveniada com a Prefeitura de Quixadá, em que foi possível, por meio da condução do coordenador e de alguns dos seus bolsistas, que os discentes convivessem com situações de ensino de conteúdos matemáticos através de estratégias lúdicas. A imagem abaixo retrata um momento dessa atividade, realizada em uma tarde de visita dessa turma na própria FECLESC.

Figura 4 - Atividade do LaboMática com os alunos visitantes.

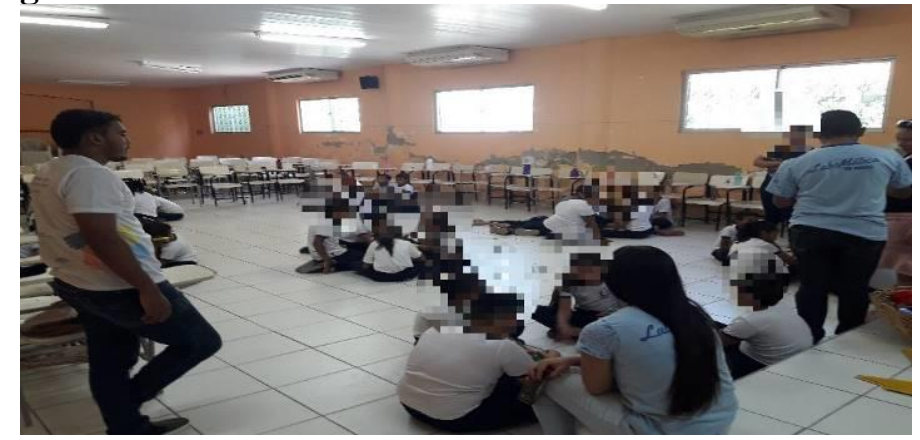

Fonte: Autores (2020).

Conforme já relatamos, uma das atividades incentivadas e realizadas por meio das atividades de extensão é a iniciação à pesquisa, a partir do trabalho do Grupo de Estudos em Educação Matemática - GEEM, também associado ao LaboMática, o qual trabalha, principalmente, com seminários temáticos sobre diversos assuntos, como Psicologia, Matemática e temas relevantes ao ensino e à Educação Matemática, esta sendo nosso foco principal. As atividades do GEEM são realizadas na FECLESC, mas também como ações do Programa de Extensão, abertas à comunidade externa. 
Assim, destacamos a importância da pesquisa científica, pois o Programa instiga a produção de resumos e artigos para a apresentação em eventos, uma forma de mostrar para a sociedade as ações que vêm sendo desenvolvidas na universidade. Além de tudo isso, os estudantes têm contato mais cedo com a produção científica, o que contribui bastante para a produção da monografia ou do trabalho de conclusão do curso, atividade em que os estudantes, de modo geral, encontram muitas dificuldades.

\section{Atividades desenvolvidas pelo Programa de Extensão na comunidade externa}

Ao longo dos anos de 2018 e 2019, o Programa de Extensão desenvolveu ações em algumas escolas de Quixadá, com o objetivo de auxiliar os professores em exercício na sala de aula, utilizando outras maneiras de ensinar e de os alunos compreenderem a Matemática, tonando-a mais significativa na percepção desses discentes e também ajudando-os, propiciando-lhes novas experiências no aprendizado dos conteúdos matemáticos.

Umas dessas atividades acontecera em maio de 2018, quando os envolvidos no Programa de Extensão foram a uma escola de Ensino Médio da rede estadual de ensino, em Quixadá, com o propósito de participar das atividades alusivas ao Dia Nacional da Matemática, em que foram realizadas algumas ações, uma delas representadas na figura abaixo, da apresentação de uma esquete teatral.

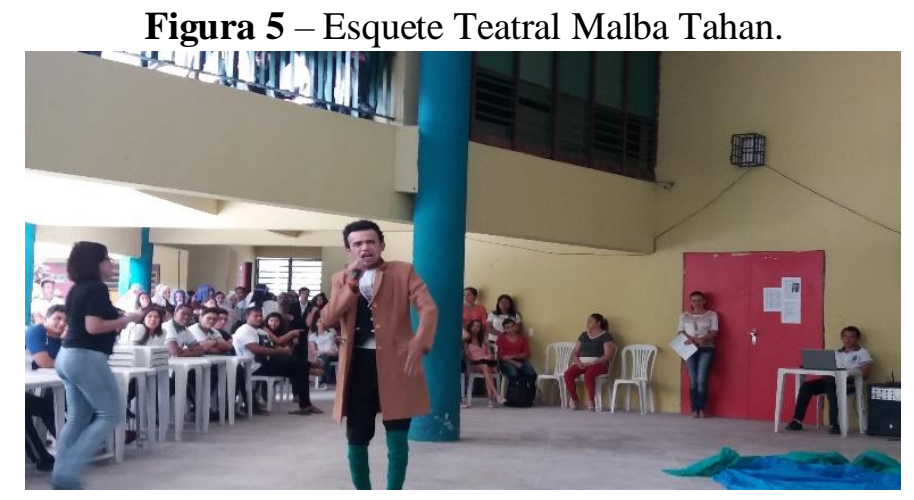

Fonte: Autores (2020).

Essa esquete foi encenada por um estudante de Pedagogia, bolsista de extensão, com base no Cordel Malba Tahan: o homem que calculava e contava histórias (CALIXTO, 1999). Com essa atividade, foi feita a abertura do evento alusivo ao Dia 

Contribuições do Programa de Extensão em Educação Matemática na FECLESC e na comunidade externa

Nacional da Matemática, 6 de maio, dia criado em homenagem ao nascimento do Professor Júlio César de Mello e Souza, o Malba Tahan, pela sua contribuição à Educação Matemática, no Brasil e em outros países.

Figura 6 - Oficina com o uso do Tangram.

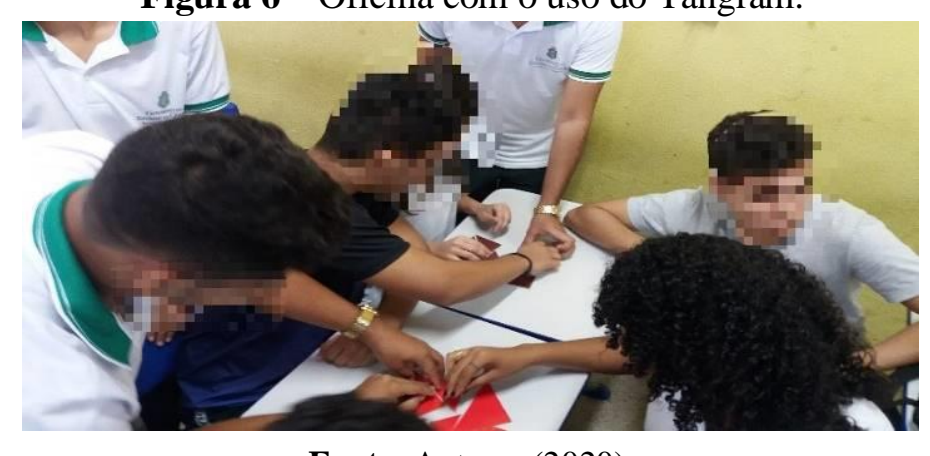

Fonte: Autores (2020).

Essa figura é um momento da oficina Uso do Tangram no ensino de Matemática, ministrada por alunos do curso de Matemática. Essa ação demonstra uma habilidade desses estudantes, obtida no ou por meio do LaboMática, na construção e no manuseio de materiais didáticos, que têm contribuído inclusive em suas atividades de estágio supervisionado, em que utilizam tais recursos.

Figura 7 - Oficina com o uso do Ábaco.

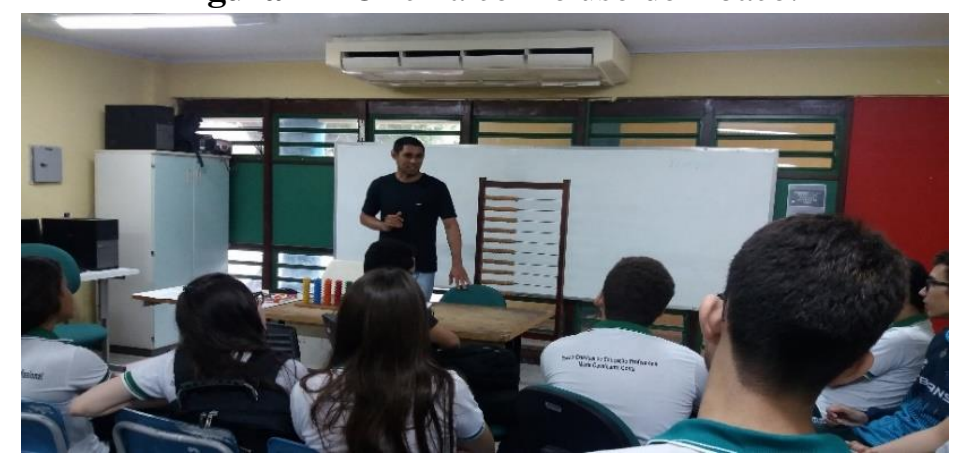

Fonte: Autores (2020).

Essa última figura é o registro de um momento da oficina O Ábaco $e$ o desenvolvimento do raciocínio lógico. Nesse evento, também foi ministrada uma palestra com o tema Ensino de Matemática e Cidadania. Essas duas últimas atividades tiveram à frente dois professores de Matemática, formados na FECLESC, estudantes que contribuíram com o LaboMática, logo no momento de sua criação, em 2008. 
Essas atividades representam atividades práticas na formação inicial dos licenciandos e de alunos do Ensino Médio, aprimorando seus conhecimentos através de materiais didáticos. Isso demonstra a relevância dessa ação de extensão, pois os bolsistas aliaram teoria e prática, contribuindo com a educação na comunidade externa e tendo o contato direto com seus futuros discentes, ocasião essencial na formação inicial desses graduandos.

Outra instituição parceira na realização do Programa de Extensão foi uma escola de Ensino Infantil e Fundamental da zona rural de Quixadá. No decorrer de, aproximadamente, quatro meses, a instituição recebeu semanalmente os bolsistas e o coordenador da atividade de extensão, com o objetivo de colaborar tanto com professores como com alunos dessa instituição. Os bolsistas ficaram divididos da seguinte forma: dois na turma de $5^{\circ}$ ano e um na turma de $9^{\circ}$ ano, ministrando aulas, com a presença dos professores titulares da sala, utilizando metodologias diferentes daquelas comumente usadas pela instituição, buscando fazer com que os docentes também vivenciassem aquele método de ensino e que os alunos aperfeiçoassem a aprendizagem dos conteúdos que eles sentiam mais dificuldades na disciplina de Matemática.

Ao longo desses meses, foram desenvolvidas várias ações didáticas com essas turmas. Para exemplificarmos, observamos uma atividade que foi aplicada no conteúdo de Área e Perímetro, na turma de $5^{\circ}$ ano, em que foi utilizado o material didático Áreas $e$ Potências, que é formado por figuras geométricas, como trapézio, triângulos, quadrados e retângulos. Com esse material, as crianças observam, concretamente, a diferença de área e perímetro. A seguir, apresentamos a imagem de um dos momentos vividos na sala de aula com a turma.

Figura 8 - Aula com utilização do material Áreas e Potências.

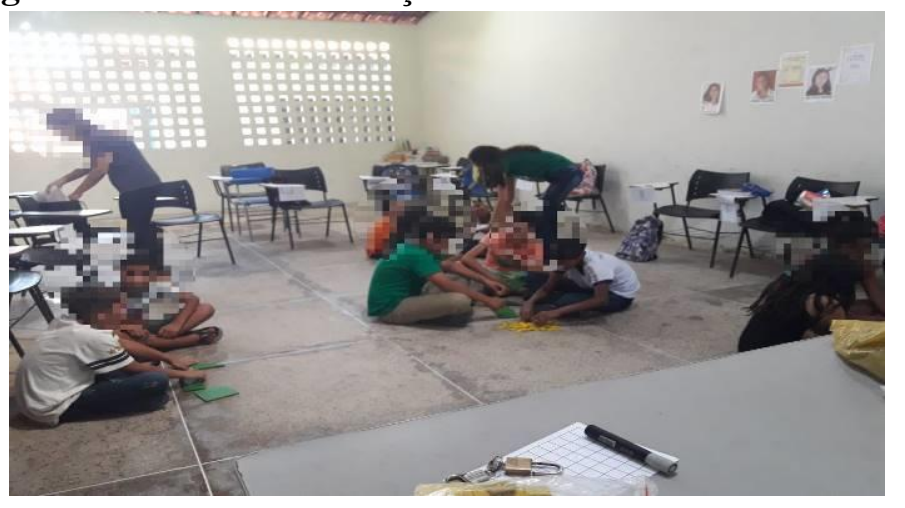


Fonte: Autores (2020).

Ao presenciarmos o desenvolvimento dessa ação, constatamos o envolvimento dos discentes com o uso do material didático ainda não existente naquela instituição. Isso demonstra, mais uma vez, a contribuição do Programa de Extensão para o ensino de Matemática. Desse modo, queremos ressaltar a importância dessa atividade na formação inicial. Os bolsistas participaram da aplicação de uma metodologia diferenciada no ensino de Matemática, uma vivência primordial para utilização ou adaptação no futuro ambiente de trabalho, para viver as vantagens e os desafios da profissão docente. Assim, concordamos com Freire e Coelho (2018) ao afirmarem que:

\footnotetext{
Para que uma formação aconteça de maneira completa, o estudante precisa mais que o conhecimento específico da sua área acadêmica. É necessário também que ele conheça o meio no e com o qual ele vai trabalhar. Nesse sentido, é extremamente necessário para o discente essa parceria Universidade/comunidade externa; no caso dos licenciandos, a parceria Universidade/escola (FREIRE; COELHO, 2018, p. 2).
}

É por meio de experiências como essas que o Programa em discussão faz os graduandos terem a oportunidade de vivenciar a prática docente, dando-lhes a possibilidade de conhecer o cenário atual do ensino de Matematica. Consideramos, também, que os bolsistas são instigados a irem a eventos e, nesses, eles apresentam trabalhos com reflexões sobre as ações desenvolvidas e participam de palestras, minicursos, entre outras atividades, para que se aperfeiçoem cada vez mais em seus fazeres docentes.

Nos dois anos investigados, foi identificada a presença dos bolsistas nos seguintes eventos científicos: II Jornada de Matemática do Instituto Federal do Ceará (IFCE), campus Cedro-CE, em 2018; Semana Universitária da UECE, em 2018 e 2019; e I Simpósio da Matemática do Instituto de Formação de Educadores (IFE), campus Brejo Santo-CE, este pertecente à Universadade Federal do Cariri (UFCA), em 2019. Observamos, na foto abaixo, os bolsistas, em 2019, apresentando-se na XXIV Semana Universitária da UECE. 
Figura 9 - Bolsistas em atividade de Comunicação Científica.

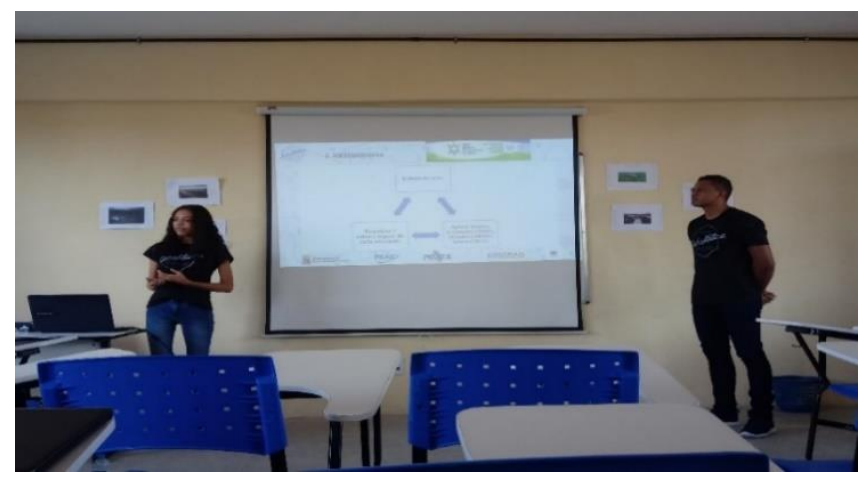

Fonte: Autores (2020).

Diante do exposto neste artigo, podemos observar como o Programa de Extensão está fazendo a diferença na formação de seus bolsistas, pois os prepara com a prática e ainda acrescenta no currículo o rigor da pesquisa científica, parte também essencial na formação de um professor, porque permite que ele reflita sobre sua prática, assim percebendo erros e acertos. Dessa maneira, concordamos com Souza et al. (2011, p. 92), ao considerarem que: "Estimular a pesquisa nos professores é um processo que deve ser considerado no dia a dia deles [...]".

Em relação às atividades exercidas nas escolas, notamos a importância das mesmas na formação inicial dos bolsistas, uma vez que elas promoveram o encontro do conhecimento desenvolvido dentro da universidade com a prática executada no âmbito escolar. Levando em conta a participação de alunos e professores nas escolas, percebemos o Programa rompendo os muros da universidade e também proporcionando experiências docentes e de iniciação científica, atendendo aos três pilares da universidade: ensino, pesquisa e extensão.

Nesse contexto, ressaltamos a relevância desse Programa de Extensão, visto que ele proporciona uma ação lado a lado entre universidade e comunidade externa, situação essa necessária e indispensável para fortalecer e complementar a formação inicial e continuada do professor, tendo como resultado melhorar a aprendizagem por parte dos alunos da Educação Básica. 


\section{Considerações finais}

Retornando ao objetivo da investigação, é notório o quanto o Programa de Extensão: Formação Continuada em Educação Matemática, por meio das atividades desenvolvidas, é significativo para todos os envolvidos em suas ações, dos bolsistas ao público participante. Assim, salientamos como a implantação de programas como esse é importante. As iniciativas e a manutenção dessas atividades devem ser cada vez mais proporcionadas às instituições públicas de ensino, pois as mesmas aproximam a universidade da comunidade externa, sendo fator fundamental para a formação inicial dos graduandos/licenciandos, fornecendo-lhes suporte, a partir da convivência com docentes em exercício.

É importante ressaltar o conhecimento adquirido pelos bolsistas durante o trajeto dessas atividades, já que, através delas, os mesmos estão obtendo experiências construtivas para sua formação inicial e são extremamente válidas para a sua futura atuação dentro da escola. Com as observações, constatamos o envolvimento da equipe que compunha o Programa de Extensão, sempre dialogando e contribuindo uns com os outros, nas atividades de ensino, pesquisa e extensão.

Portanto, a participação nesse Programa e a produção deste trabalho enriqueceram, de forma significativa, nossa formação, porque vivenciamos várias atividades que objetivaram aperfeiçoar o ensino de Matemática nas escolas de ensino básico, empenhando-nos em ajudar os principais agentes da educação, que são os professores, nesse caso mais específico, os docentes que ensinam Matemática. Esses precisam muito de subsídios didático-metodológicos, para tentar mudar a aversão que os alunos têm em relação a essa disciplina.

Dessa maneira, esperamos que as experiências relatadas, neste trabalho, ajudem os leitores, especialmente, os licenciandos, a saberem mais sobre a importância da extensão universitária, percebendo-a com uma peça fundamental na formação do professor, pois ela os aproxima do fazer docente e, ainda, rompe a distância entre universidade e comunidade externa, entre universidade e escola, integração imprescindível na formação de professores. Importa, também, perceber a relevância da relação entre as atividades de ensino, pesquisa e extensão, ações complementares na formação superior. 

Contribuições do Programa de Extensão em Educação Matemática na FECLESC e na comunidade externa

\section{Referências}

CALIXTO, G. Malba Tahan: o homem que calculava e contava histórias. VI Semana de Ciências do Sertão Central. Quixadá: FECLESC, 1999. Ano X da FECISC.

FREIRE. D. F; COELHO, M. G. M. O Programa de Extensão do LABOMÁTICA/FECLESC e sua influência na formação inicial de seus bolsistas. In: Jornada de Matemática do IFCE, campus Cedro, 2., 2018, Ceará. Anais... [s.n], 2018, p.1-6.

LORENZATO, S. Laboratório de ensino de matemática e materiais didáticos manipuláveis. In: LORENZATO, Sérgio (Org.). Laboratório de Ensino de Matemática na formação de professores. Campinas, SP: Autores Associados, 2006. p. 3-38.

LORENZATO, S. Para aprender matemática. 2. ed. rev. Campinas, SP: Autores Associados, 2008.

PENTEADO, M. G.; BORBA, M. de C. Informática e Educação Matemática. 5. ed.; 2. reimp. Belo Horizonte: Autêntica Editora, 2016. 104p.

SOUZA, A. A. de et al. Refletindo sobre a importância da pesquisa na formação e na prática docente. Revista Eletrônica de Ciências e Educação-RECE, Campo Largo, v. 10, n. 1, p. 77-97, jul. 2011. 